\title{
STUDIES IN STEROID METABOLISM. XIX. THE $a$-KETOSTEROID EXCRETION PATTERN IN NORMAL MALES ${ }^{1}$
}

\author{
BY KONRAD DOBRINER 2
}

\author{
THE DATA WERE ASSEMBLED AND THE MANUSCRIPT PREPARED BY: 8 \\ ATTALLAH KAPPAS, 4 C. P. RHOADS AND T. F. GALLAGHER \\ (From the Laboratories of the Sloan-Kettering Institute for Cancer Research, \\ New York, New York)
}

(Submitted for publication April 6, 1953; accepted May 29, 1953)

The urinary steroids afford a means for evaluation of the production of steroid hormones by the adrenal and gonads. Any alteration in either rate of type of hormone production by the glands resulting from specific disease or from hormonal therapy therefore must be manifest by qualitative or quantitative change in the excretion of steroid hormone metabolites. In order to delineate the composition of these metabolites in normal healthy subjects, the present investigation describing the $a$-ketosteroid excretion pattern was undertaken.

\section{MATERIALS AND METHODS}

Twenty normal males, ranging in age from 21 to 76 , were studied. Of this number, eighteen were White and one was Negro; Subject D31 was a Nisei. Subjects C21 and M21 were normal males hospitalized at the Peter Bent Brigham Hospital, Boston, Massachusetts, for the purpose of studying some of the metabolic effects of oral Cortisone and intravenous ACTH; Subjects K31, R32, R63, C64, M65, and M72 were subjects of similar study at the Baltimore City Hospitals, Baltimore, Maryland. Only control periods of these eight subjects are reported here. The remainder of the subjects are, or were, employees of this Institute, working and in apparent good health. The details of urine collection and handling in this laboratory have been reported previously (1). Urine was collected

\footnotetext{
1 The authors gratefully acknowledge the assistance of grants from the American Cancer Society (on recommendation of the Committee on Growth of the National Research Council), the Commonwealth Fund, the Anna Fuller Fund, the Lillia Babbitt Hyde Foundation, and the National Cancer Institute of the National Institutes of Health of the United States Public Health Service.

2 Konrad Dobriner died March 10, 1952.

8 So far as we are aware, the interpretation of the data and the conclusions drawn are in essential agreement with the views held by the late Dr. Dobriner.

- Research Fellow of the American Cancer Society upon recommendation of the Committee on Growth of the National Research Council.
}

for periods ranging from 1 to 198 days, although only four subjects had urine collections longer than 20 days.

Hydrolysis: During the course of the study, and with the aim of providing more reliable techniques, several hydrolytic procedures have been used. A short description of the different methods of hydrolysis follows.

Method A: Stage 1. The urine was adjusted to $\mathrm{pH}$ 1 with concentrated sulfuric acid. To this solution, concentrated sulfuric acid equaling 5 per cent of the original volume was added. The urine was then heated under reflux for one-half hour. After cooling, the urine was continuously extracted with ether for 24 hours.

Stage 2. The ethereal extract was washed several times with saturated sodium bicarbonate solution.

Stage 3. The other solution from Stage 2 was washed several times with $2 \mathrm{~N}$ sodium hydroxide.

Stage 4. The ether solution from Stage 3 was washed with 10 per cent hydrochloric acid and with water, until the washings were neutral. Aqueous and acid extracts were discarded. The ether was removed under diminished pressure and the residue obtained was referred to as the "crude neutral steroidal fraction."

Stage 5. "Crude acidic" and "crude phenolic" fractions were obtained from the alkali soluble material from Stages 2 and 3 by methods reported previously (1) and stored for future work. "Crude acidic" and "crude phenolic" fractions were prepared from alkali soluble extracts in Methods B, C, and D as well.

Method B: Stage 1. The urine was adjusted to $\mathrm{pH} 1$ with concentrated sulfuric acid and continuously extracted with ether for 48 hours.

Stage 2. The ether solution was extracted with saturated sodium bicarbonate as in Method A, Stage 2. The ether solution remaining was processed to the "crude neutral steroidal fraction" (as in Method A, Stages 3 and 4).

Stage 3. The sodium bicarbonate wash from Stage 2 was acidified to $\mathrm{pH} 1$ with sulfuric acid, 5 per cent by volume of concentrated sulfuric acid was added, and the solution heated under reflux for one-half hour. After cooling, it was continuously extracted with ether for 24 hours, processed as in Method A, Stages 2, 3, and 4, and the "crude neutral fraction" was obtained.

Stage 4. The spent urine after Stage 1 was acidified with 5 per cent of its volume of concentrated sulfuric acid, 
heated under reflux for one-half hour and extracted with ether for 24 hours. This ether extract was treated as in Method A, Stages 2, 3, and 4, and the "crude neutral fraction" was obtained.

This method of hydrolysis yielded three "crude neutral fractions"; one was obtained by "mild" hydrolysis and two were obtained by "vigorous" acid hydrolysis.

Method C: Stage 1. The initial acidification and extraction of urine and spent urine was that followed in Method 2, Stages 1, 2, and 4.

Stage 2. The sodium bicarbonate wash (obtained as in Method 2, Stage 3) was adjusted to $\mathrm{pH} 5$ with concentrated sulfuric acid, and then 10 per cent by volume of sodium acetate buffer at pH 5 and 300,000 units per liter of solution of beef liver $\beta$-glucuronidase were added. The solution was incubated at $37^{\circ}$ for 48 hours. After incubation, the solution was adjusted to $\mathrm{pH} 1$ with concentrated sulfuric acid and was extracted with ether for 48 hours. The "crude neutral fraction" from this ether extract was obtained as in Method A, Stages 2, 3, and 4.

Stage 3. The sodium bicarbonate wash from Stage 2, above, was processed and another "crude neutral fraction" was obtained (as in Method A, Stages 1, 2, 3, and 4).

Stage 4. The aqueous residue after ether extraction from Stage 2 was treated as in Method A, Stages 1, 2, 3, and 4, and a final "crude neutral fraction" was obtained.

This hydrolytic method yielded five crude neutral fractions; two of these were obtained by "mild" hydrolysis, and three were obtained by "vigorous" acid hydrolysis.

Method D: Stage 1. The urine was adjusted to $\mathrm{pH} 5$ with concentrated sulfuric acid and 10 per cent by volume of sodium acetate buffer at $\mathrm{pH} 5$ and 300,000 units per liter of solution of beef liver $\beta$-glucuronidase were added. The solution was incubated at $37^{\circ}$ for 48 hours. After incubation, the urine was adjusted to $\mathrm{pH} 1$ with concentrated sulfuric acid and extracted with ether for 48 hours. The "crude neutral fraction" was obtained from this ethereal extract as in Method A, Stages 2, 3, and 4.

Stage 2. The spent urine after Stage 1, was treated as in Method A, Stages 1, 2, 3, and 4 and the "crude neutral fraction" was obtained.

Stage 3. The sodium bicarbonate wash from Stage 1 was treated as in Method C, Stage 2, and the ethereal extract was obtained.

Stage 4. The ethereal extract obtained in Stage 3, above, was treated as in Method A, Stages 2, 3, and 4, and the "crude neutral fraction" obtained.

Stage 5. The sodium bicarbonate extract from Stage 4 was treated as in Method A, Stages 1, 2, 3, and 4, and the "crude neutral fraction" obtained.

Stage 6. The aqueous residue after ether extraction from Stage 3, above, was treated as in Method A, Stages $1,2,3$, and 4, and a "crude neutral fraction" obtained.

This method of hydrolysis yielded five crude neutral fractions; two of these fractions were obtained under conditions of "mild" hydrolysis and three were obtained by "vigorous" acid hydrolysis.

Fractionation: The "crude neutral steroid fractions" obtained after these various hydrolytic procedures were separated into ketonic and non-ketonic fractions by means of Girard's "Reagent T" and into $\alpha$ and $\beta$-ketosteroid fractions by precipitation with digitonin. These methods have been described in detail (1). The ketosteroid fractions were then separated by chromatography on alumina or silica gel columns. When Method B was used, the three "crude neutral steroid fractions" were separately fractionated and chromatographed. The sum of the values obtained for individual steroids from each fraction was used for the pattern. When Method C or D was used, the "crude neutral steroid fractions" obtained after "mild" hydrolysis were combined prior to fractionation and chromatography. Similar but separate treatment was accorded the "crude neutral steroid fractions" obtained after "vigorous" acid hydrolysis. After separation into ketonic and non-ketonic material, the ketonic portion from "mildly" hydrolyzed extracts was partitioned between benzene and water according to the procedure of Mason (2). Separation into $\alpha$ and $\beta$ subfractions with digitonin was done on the benzene soluble material and only the $\alpha$-ketosteroids were included in the pattern. The vigorously hydrolyzed fractions were not partitioned between benzene and water. The $\alpha$-ketosteroids from the two types of hydrolytic procedures were sometimes combined prior to chromatography but more frequently separate chromatograms were made and the sum of the individual values was used for the pattern.

The water extracts, obtained from benzene-water partition (Methods C and D) were chromatographed separately, after acetylation with pyridine and acetic anhydride at room temperature. The water extraction procedure is a recent addition to the methodology and relatively few urine extracts were processed through this stage. Therefore the values for substances normally encountered in this fraction which are lacking in Table I and Figure 2 were omitted because the fraction was unavailable.

Each individual fraction from the chromatogram was analyzed by infrared spectrometry and quantitation of the separated steroids was done by the Zimmerman reaction (as modified by Callow, Callow, Emmens, and Stroud $[3,4]$ and Talbot, Butler, MacLachlan, and Jones [5]). Since ketosteroids differ somewhat in chromogenic value, appropriately determined factors were used to correct the color values from milligrams of dehydroisoandrosterone, used as the standard, to milligrams of the actual compound determined in the chromatographic fraction. Fractions obtained from the water soluble extracts were analyzed by ultraviolet spectrometry for compounds containing an $\alpha, \beta$-unsaturated ketone (Compounds $\mathrm{E}$ and $\mathrm{F}$ ) and by the Zimmerman reaction with appropriate factors, for saturated compounds (tetrahydro $E$ and $F$ ).

Traces of $3 \beta$-etiocholanolone often appear in $\alpha$-ketonic fractions. Though this compound is quantitatively precipitated by digitonin when pure, this is not the case with urinary extracts. Thus the figures reported do not estimate total daily excretion of this steroid. The separation of androstanedione and etiocholanedione from each other and from $3 \beta$-etiocholanolone is incomplete and quantitation is distorted by impurities, eluted from this portion of 
TABLE I

The urinary steroid excretion pattern in normal males

\begin{tabular}{|c|c|c|c|c|c|c|c|c|c|c|}
\hline Compounds & \multicolumn{10}{|c|}{ Milligrams per 24 hours } \\
\hline $\begin{array}{l}\text { Total } C_{19} \text { 11-oxy steroids } \\
\text { Total } C_{19} 11-\text { desoxy steroids } \\
\text { Compounds E \& F } \\
\text { Tetrahydro E \& F }\end{array}$ & $\begin{array}{r}2.8 \\
14.8\end{array}$ & $\begin{array}{r}2.8 \\
12.2\end{array}$ & $\begin{array}{r}.6 \\
4.0\end{array}$ & $\begin{array}{r}2.6 \\
10.4\end{array}$ & $\begin{array}{l}2.6 \\
7.0\end{array}$ & $\begin{array}{l}3.4 \\
8.4\end{array}$ & $\begin{array}{r}.8 \\
4.3\end{array}$ & $\begin{array}{r}1.2 \\
3.6 \\
.3 \\
.4\end{array}$ & $\begin{array}{r}2.1 \\
5.7 \\
.3 \\
1.0\end{array}$ & $\begin{array}{r}3.6 \\
12.9\end{array}$ \\
\hline 17-Hydroxypregnanolone & 一 & 一 & - & 一 & 一 & - & 一 & - & - & 一 \\
\hline 11-Ketoandrosterone & -8 & $\overline{1}$ & $\operatorname{tr}$ & - & .1 & .6 & - & tr. & 一 & $\operatorname{tr}$ \\
\hline $\begin{array}{l}\text { 11-Ketoetiocholanolone } \\
\text { 11-Hydroxyetiocholanolone }\end{array}$ & $\begin{array}{l}.8 \\
.4\end{array}$ & 1.1 & .5 & 1.3 & 1.0 & 1.2 & .7 & .2 & .6 & 1.8 \\
\hline 11-Hydroxyandrosterone & 1.6 & 1.7 & .1 & 1.3 & 1.5 & 1.6 & .1 & 1.0 & 1.5 & 1.8 \\
\hline Etiocholanolone & 7.6 & 6.0 & 2.7 & 6.9 & 3.3 & 4.7 & 2.3 & 1.8 & 3.1 & 7.6 \\
\hline Androsterone & 7.0 & 6.2 & 1.0 & 3.0 & 3.0 & 3.0 & 1.6 & 1.8 & 2.5 & 4.3 \\
\hline "Preg. group" & - & - & .4 & - & 1.8 & - & .7 & - & - & 1.0 \\
\hline 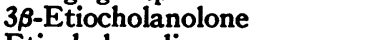 & 一 & 一 & .1 & - & .2 & 一 & .1 & 一 & 一 & .3 \\
\hline Etiocholanedione & .1 & tr. & .1 & tr. & .2 & tr. & .2 & tr. & tr. & .4 \\
\hline Androstanedione & .1 & tr. & .1 & .5 & .3 & .7 & .1 & tr. & .1 & .3 \\
\hline$\% \beta$ of $\alpha+\beta$ & 4.5 & 7.7 & 4.4 & 10.1 & 6.0 & 7.8 & 3.4 & 20.2 & 6.1 & 9.7 \\
\hline $\boldsymbol{\beta}$-Ketonic KS & 1.1 & 1.6 & .4 & 2.0 & .8 & 1.3 & .3 & 1.9 & .7 & 2.3 \\
\hline$\alpha$-Ketonic KS & 23.5 & 19.3 & 8.6 & 17.8 & 12.5 & 15.4 & 8.6 & 7.5 & 10.8 & 21.4 \\
\hline Ketonic KS & 24.3 & 23.7 & 9.8 & 22.6 & 15.5 & 17.1 & 11.2 & 12.9 & 13.1 & 26.1 \\
\hline Crude KS & 28.8 & 29.8 & 27.4 & 22.8 & 21.7 & 19.4 & 15.3 & 20.2 & 22.5 & 29.0 \\
\hline $\begin{array}{l}\text { Hydrolysis } \\
\text { Collection days }\end{array}$ & D & $\begin{array}{l}\mathrm{D} \\
9\end{array}$ & B* & $\underset{* *}{\mathbf{A}}$ & A & A & A & C & C & \\
\hline $\begin{array}{l}\text { Collection days } \\
\text { Patient-age }\end{array}$ & $\begin{array}{c}9 \\
\text { M21 }\end{array}$ & $\begin{array}{c}9 \\
\text { C21 }\end{array}$ & B21 & Y27 & $\stackrel{* *}{*}$ & 21 & $\stackrel{* *}{21}$ & 15 & $\begin{array}{c}15 \\
R_{32}\end{array}$ & 33 \\
\hline t-age & & & & $\mathbf{Y} 20$ & N30 & Gso & D31 & K31 & R32 & D35 \\
\hline
\end{tabular}

* Hydrolyzed according to Method B, eliminating Stage 3.

** Average of values of replicate patterns.

TABLE I-Continued

\begin{tabular}{|c|c|c|c|c|c|c|c|c|c|c|}
\hline \multirow{3}{*}{$\begin{array}{l}\text { Compounds } \\
\text { Total } C_{19} 11 \text {-oxy steroids } \\
\text { Total } C_{19} 11-\text { desoxy steroids } \\
\text { Compounds E \& F } \\
\text { Tetrahydro E \& F } \\
\text { 17-Hydroxypregnanolone }\end{array}$} & \multicolumn{10}{|c|}{ Milligrams per 24 hours } \\
\hline & $\begin{array}{r}1.1 \\
10.9\end{array}$ & $\begin{array}{l}2.4 \\
7.6\end{array}$ & $\begin{array}{l}1.3 \\
7.2\end{array}$ & $\begin{array}{l}1.4 \\
4.1\end{array}$ & $\begin{array}{l}1.4 \\
4.9\end{array}$ & $\begin{array}{l}3.2 \\
4.2\end{array}$ & $\begin{array}{r}.8 \\
1.7 \\
.4 \\
.6\end{array}$ & .9 .9 & $\begin{array}{l}4.1 \\
6.2\end{array}$ & $\begin{array}{l}.5 \\
.8\end{array}$ \\
\hline & - & 一 & 一 & - & - & - & - & - & - & 一 \\
\hline 11-Ketoandrosterone & tr. & .8 & .3 & $\operatorname{tr}$ & - & $\overline{12}$ & - & $\operatorname{tr}$. & -9 & $\operatorname{tr}$ \\
\hline 11-Hydroxyetiocholanolone & $\underline{1.0}$ & $\underline{1.0}$ & $\stackrel{.4}{-}$ & $\stackrel{-1}{-}$ & $\stackrel{-}{-}$ & $\begin{array}{l}1.2 \\
1.0\end{array}$ & $\stackrel{.3}{-}$ & $\stackrel{.0}{-}$ & .9 & $\dot{\mathrm{tr}}$. \\
\hline 11-Hydroxyandrosterone & .1 & .1 & .6 & .7 & .9 & 1.0 & .5 & .3 & 2.9 & tr. \\
\hline Etiocholanolone & 8.0 & 3.7 & 4.8 & 2.6 & 2.5 & 2.1 & 1.2 & 1.7 & 4.0 & .5 \\
\hline Androsterone & 2.7 & 3.4 & 1.6 & 1.1 & 2.4 & 2.1 & .5 & .4 & 2.2 & .2 \\
\hline "Preg. group" & .8 & 2.2 & 1.7 & 1.5 & - & - & 一 & .7 & - & .5 \\
\hline $3 \boldsymbol{\beta}$-Etiocholanolone & .1 & .1 & .2 & .1 & - & - & tr. & tr. & - & .1 \\
\hline $\begin{array}{l}\text { Etiocholanedione } \\
\text { Androstanedione }\end{array}$ & 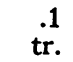 & tr. & .3 & .1 & $\begin{array}{l}\text { tr. } \\
\text { tr. }\end{array}$ & $\begin{array}{l}\operatorname{tr} . \\
\operatorname{tr}\end{array}$ & $\begin{array}{l}\text { tr. } \\
\text { tr. }\end{array}$ & $\begin{array}{l}.2 \\
.2\end{array}$ & $\begin{array}{l}\text { tr. } \\
\text { tr. }\end{array}$ & $\operatorname{tr}$ \\
\hline$\% \beta$ of $\alpha+\beta$ & 1.4 & 2.4 & 6.2 & 4.3 & 16.2 & 一 & 2.1 & 1.8 & 4.1 & 2.4 \\
\hline $\boldsymbol{\beta}$-Ketonic KS & .2 & .3 & 1.0 & .4 & 1.6 & tr. & .1 & .1 & .5 & .1 \\
\hline$\alpha$-Ketonic KS & 14.5 & 12.4 & 15.2 & 8.9 & 8.3 & 7.8 & 4.7 & 5.6 & 11.8 & 4.1 \\
\hline $\begin{array}{l}\text { Ketonic KS } \\
\text { Crude KS }\end{array}$ & 18.6 & 16.3 & $\begin{array}{l}19.2 \\
548\end{array}$ & 10.7 & 11.8 & 9.7 & $\begin{array}{r}5.2 \\
15\end{array}$ & 6.0 & 13.9 & 5.3 \\
\hline Hydrolysis & $\mathrm{A}$ & $\mathrm{B}^{*}$ & A & A & $\mathrm{C}$ & C & $\mathrm{C}$ & A & C & A \\
\hline Collection days & ** & 38 & $=$ & 4 & 15 & 9 & 15 & 5 & 9 & 5 \\
\hline Patient-age & T42 & W50 & M51 & F54 & R63' & C64 & M65 & L66 & M72 & M76 \\
\hline
\end{tabular}

the chromatographic columns. In those hydrolytic procedures employing vigorous acid hydrolysis a variable proportion of the compounds 11-hydroxyandrosterone and 11-hydroxyetiocholanolone were isolated as their $\Delta^{\theta, 11}$ unsaturated analogs. This occurred especially when hydrolytic methods $A$ and $B$ were used, though very small amounts of these unsaturated analogs sometimes are encountered when the enzymatic methods are employed, probably as a result of dehydration on the adsorbent surface.
In all cases it is evident that the sum of isolated and identified steroids does not equal that of the original $\alpha$-ketonic value. There is no evidence that this unidentified fraction contains anything more than trace amounts of ketosteroids, and the discrepancy between the "crude" and the isolated ketosteroids very probably results from the elimination of non-specific chromogens.

Terminology: The following terminology has been employed in this laboratory-and is employed in this paperfor brevity and convenience in reference: dehydroisoandro- 
sterone for 3 3 -hydroxy- $\Delta^{5}$-androstene-17-one; etiocholanedione for etiocholane-3,17-dione; androstanedione for androstane-3,17-dione ; androsterone for $3 \alpha$-hydroxyandrostane-17-one; etiocholanolone for $3 \alpha$-hydroxyetiocholane17-one; 11-hydroxyetiocholanolone for $3 \alpha, 11 \beta$-dihydroxyetiocholane-17-one; 11-hydroxyandrosterone for $3 \alpha, 11 \beta$ dihydroxyandrostane-17-one; 11-ketoetiocholanolone for $3 \alpha$-hydroxyetiocholane-11,17-dione ; 11-ketoandrosterone for $3 \alpha$-hydroxyandrostane-11,17-dione; 17-hydroxypregnanolone for $3 \alpha, 17 \alpha$-dihydroxypregnane-20-one; tetrahydro $E$ for $3 \alpha, 17 \alpha, 21$-trihydroxypregnane-11,20-dione; tetrahydro $F$ for $3 \alpha, 11 \beta, 17 \alpha, 21$-tetrahydroxypregnane-20one; Compound $E$ for 17 $\alpha, 21$-dihydroxy- $\Delta$-pregnene3,11,20-trione; Compound $F$ for $11 \beta, 17 \alpha, 21$-trihydroxy- $\Delta 4$ pregnene-3,20-dione. Preg. group refers to a specific group of eluents from alumina columns appearing immediately before androsterone and characterized by infrared spectrometry as a 20-ketosteroid containing a hydroxyl group; pregnanolone has previously been isolated from a pool of this material. This group sometimes con- tains, in addition, an unidentified 17-ketosteroid. Because the color factor for this group is high (6.5) the quantitative values may be seriously in error. In the graphs, 11-hydroxy and 17-hydroxy have been abbreviated to $11-\mathrm{OH}$ and $17-\mathrm{OH}$.

\section{RESULTS}

The quantitative data on the $a$-ketonic steroid pattern in male urine are found in Table I. Subjects are listed by initial and in ascending order of age, with hydrolytic method, length of collection, crude steroid data and the steroid excretion pattern listed in appropriate sections of the Table. The high values for crude ketosteroid excretion are the result of the relatively complete extraction from urine of both ketones and non-ketonic alcohols as well as non-specific chromogens. The

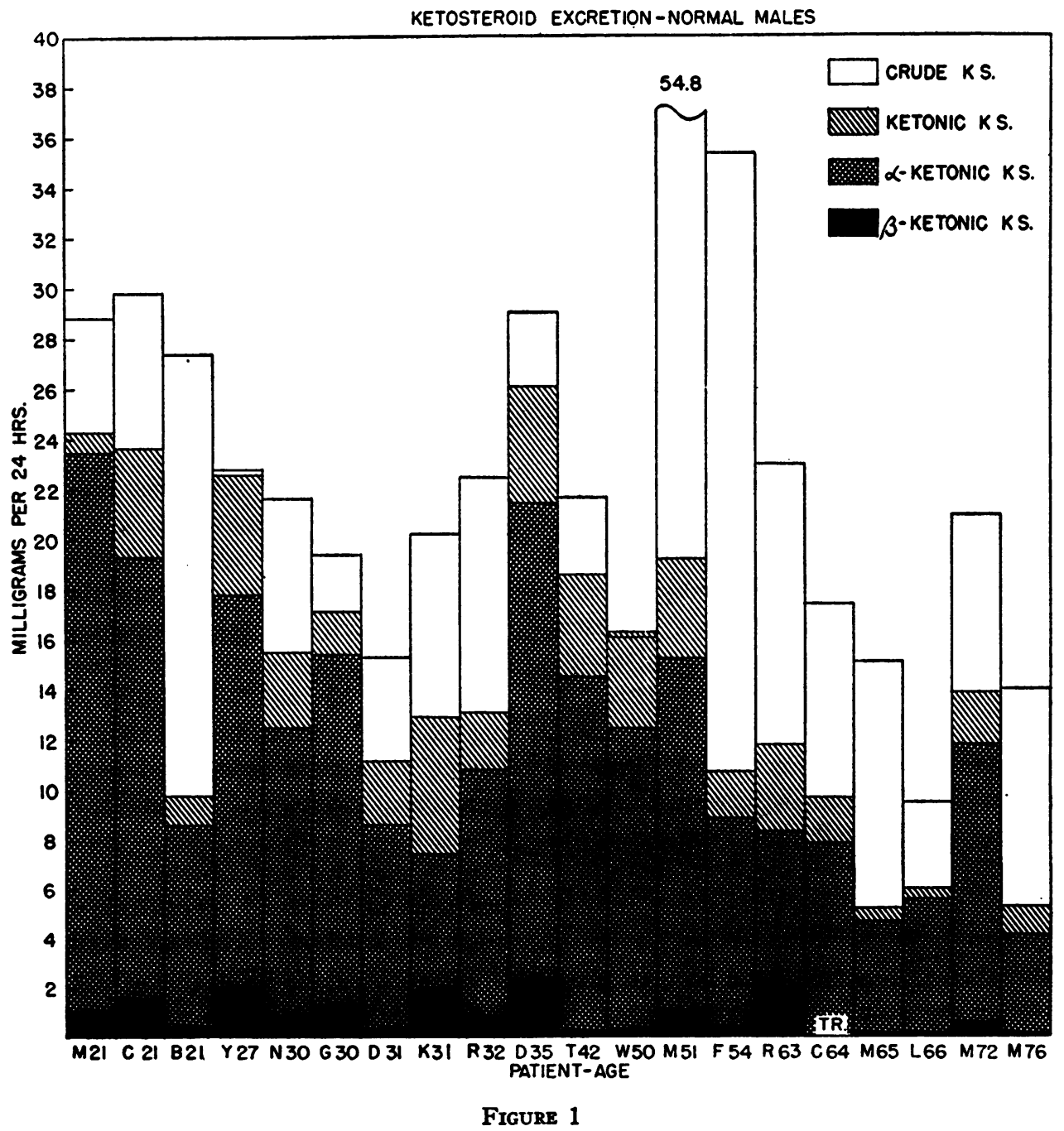




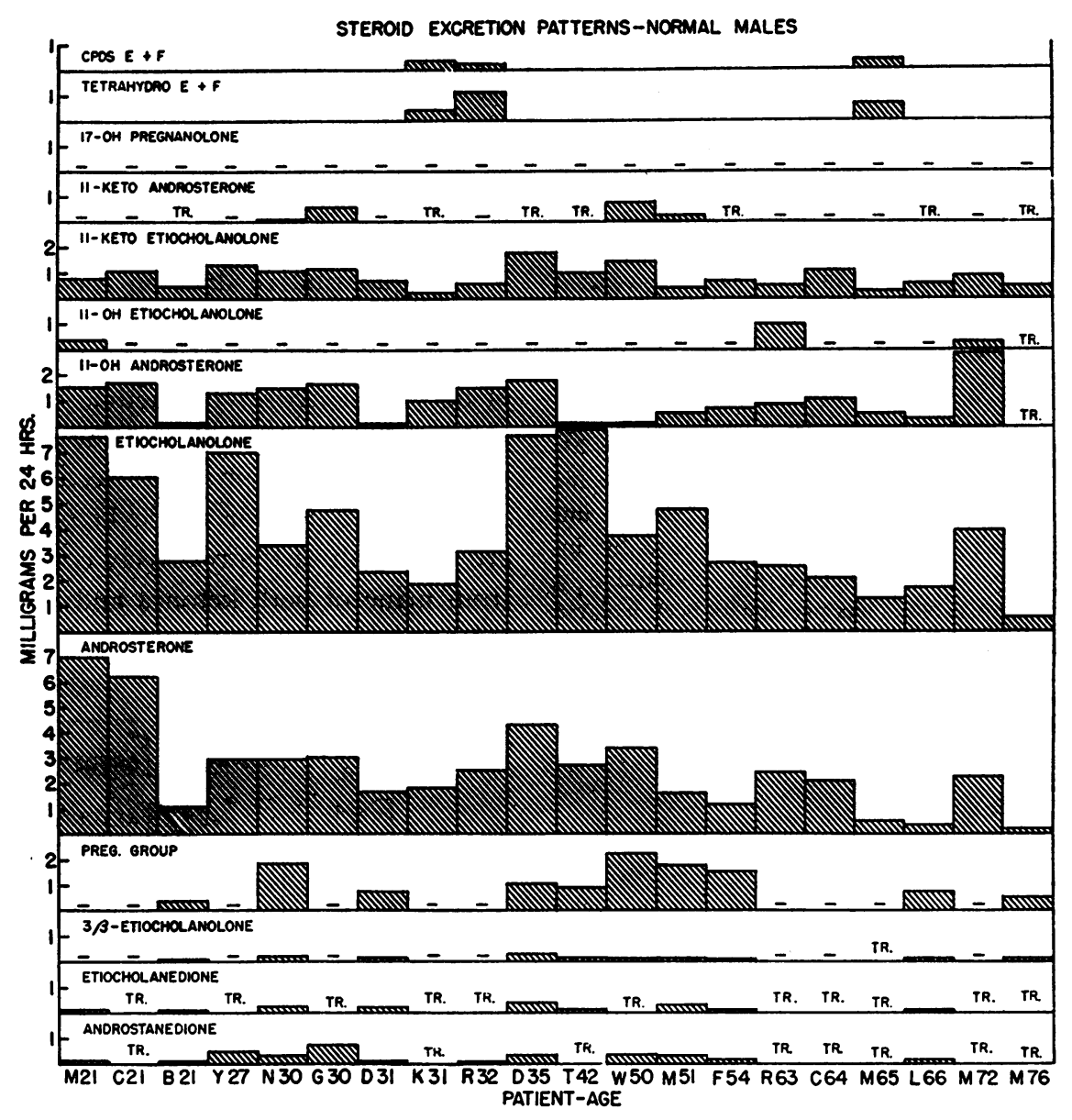

FIGURE 2

values for the ketonic fraction are more truly representative of the ketosteroids and are similar to the data of other investigators on ketosteroid excretion in normal subjects. In subjects B21, $\mathrm{Y} 27, \mathrm{~N} 30, \mathrm{D} 31$ and $\mathrm{T} 42$, the figures represent mean values of several patterns run on each subject (two, two, three, four, and three, respectively).

Figure 1 is a graphic representation of patient, age, and crude ketosteroid excretion; Figure 2 depicts the steroid excretion pattern on the same subjects, listing all isolated and identified components in milligrams per twenty-four hours.

\section{DISCUSSION}

The actual studies reported have been in progress over twelve years and during this time various alterations and improvements in technique have been introduced. Despite the progressive change in methodology, it is apparent that a fairly con- sistent pattern of results has emerged. The $a-$ ketosteroids of normal men are sufficiently descriptive of the individual to permit certain generalizations about hormones and their metabolism.

The majority of the compounds identified in the $a$-ketonic fraction can be grouped as follows: 1) Steroids having 19 carbon atoms and containing an oxygen function at carbon $11 ; 2$ ) Steroids having 19 carbon atoms and lacking an oxygen function at carbon 11. Group 1, the $\mathrm{C}_{19}$ 11-oxygenated metabolites, quantitatively the small component, may account for from 10 to as much as 45 per cent of the total identifiable material in the $a$-ketonic fraction. The hormonal precursors of the compounds found in this group are almost unquestionably products of the adrenal cortex, since there is no evidence to suggest that 11 oxygenation is a capacity of any other tissue (excepting perhaps placenta, which does not come into consider- 
ation in this series). The precursor steroid or steroids must be substances with a ketone or hydroxyl function at C-11, and probably in addition, an oxygen function at $\mathrm{C}-17$. Of the known adrenal hormones, hydrocortisone clearly meets the qualifications. Since studies of adrenal vein blood (6, 7 ), perfusion of surviving gland (8), and direct isolation (9) are in agreement that this hormone is one of the principal products of adrenocortical activity, it may be presumed that urinary steroids of Group 1 are derived chiefly from this precursor.

There is a large individual variation from subject to subject in the daily excretion of $\mathrm{C}_{19}$ compounds with an 11-oxygen function. It is evident that this range of values is not attributable to age, as shown in Figure 3. Though modal values differ somewhat, men in the age group 50 years and above excrete $C_{19}$ 11-oxygenated steroids in approximately the same amounts as men below 50 years. Thus, it would appear that adrenal function

\section{NORMAL MALES \\ EXCRETION OF $C^{19}-\|$ OXY STEROIDS}

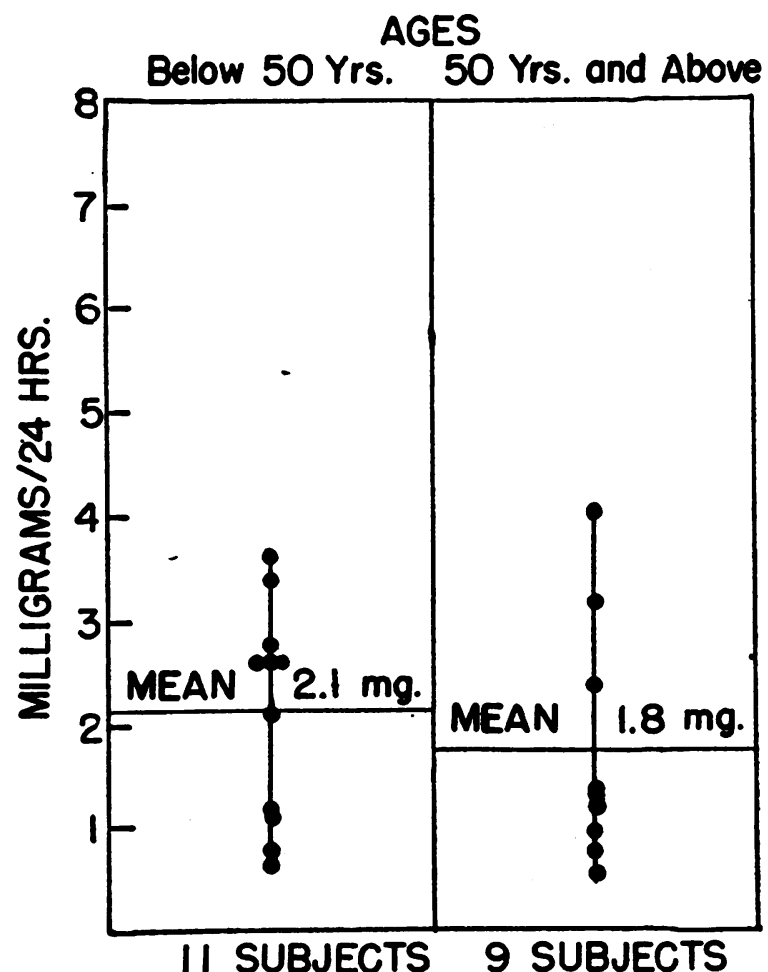

Figure 3

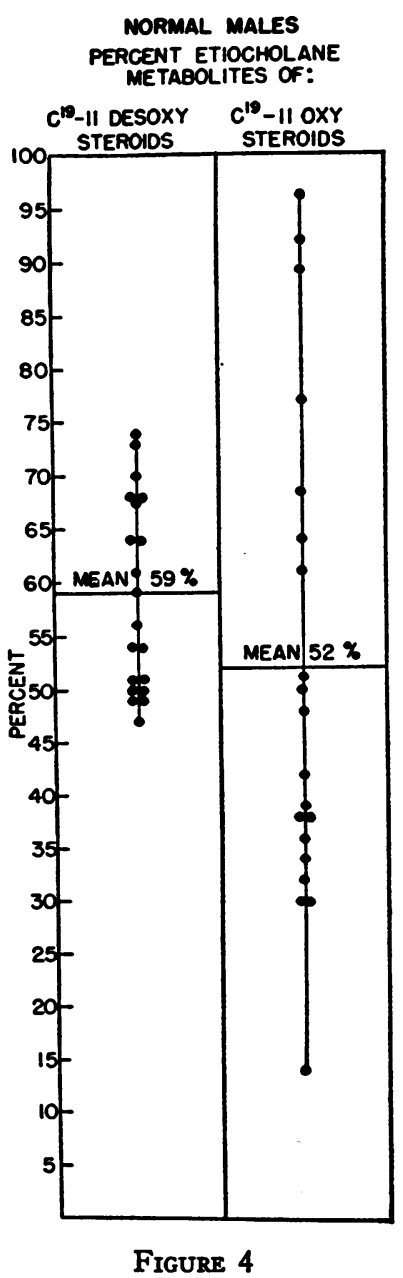

under the conditions studied, is not appreciably altered with age.

Two steroids, 11-hydroxyandrosterone and 11ketoetiocholanolone are the principal, and to all practical purposes, the only components of Group 1. Values for excretion of 11-hydroxyandrosterone range from trace amounts to $2.9 \mathrm{mg}$. per 24 hours with mean value of $1.0 \mathrm{mg}$. per 24 hours. Values for excretion of 11-ketoetiocholanolone range from $.2 \mathrm{mg}$. per 24 hours to $1.8 \mathrm{mg}$. per 24 hours with a mean value of $.8 \mathrm{mg}$. per 24 hours. There is no constant relationship of these two substances to one another in the various subjects studied. In ten of the subjects 11-hydroxyandrosterone was present in greater amounts, and in seven, 11-ketoetiocholanolone was the larger component. Figure 4 depicts the percentage of the Group 1 metabolites found in the form of derivatives of the parent hy- 


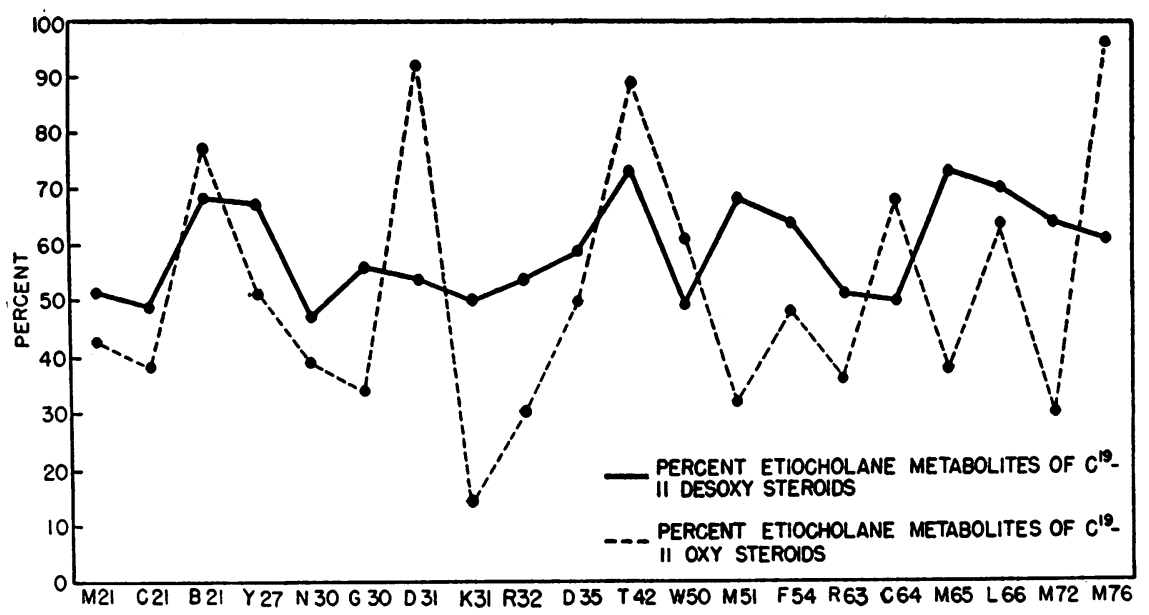

Figure 5

drocarbon etiocholane (Rings $\mathrm{A}: \mathrm{B}$-cis). It is evident that there is extremely wide variation in the per cent of metabolites excreted as this isomer. This variation appears unrelated to either age, total daily output of $C_{19} 11$-oxy steroids, or the per cent of $C_{19}$ 11-desoxy steroids excreted as this isomer (Figure 5). The significance of this variation in the type of $\mathrm{A}: \mathrm{B}$ ring juncture effected by different subjects is unknown at present.

Two other steroids are found in this group, though with considerably less regularity and in very much smaller amounts. (11-ketoandrosterone was found in trace amounts in seven, and in larger amounts in four of the twenty subjects.) Its presence does not appear related to age or the level of any other transformation product. 11-hydroxyetiocholanolone was found in the urine of four normal subjects. In three of these, it was present in considerably greater than trace amounts (M21, C64, M72) ; three out of the four subjects in whose urine it has been identified are 64 years of age or over (C64, M72, M76). The presence of 11hydroxyetiocholanolone in urine has previously been related with a high degree of significance to the existence of malignancy in the subject studied (10-12). Moreover, three subjects previously selected as normal controls and whose urine showed the presence of greater than trace amounts of 11hydroxyetiocholanolone, each developed and was treated for a malignant tumor while the present program of studies was in progress. It is known that 11-hydroxyetiocholanolone may appear in the urine of patients who have received ACTH as therapy or for study purposes (13). However, coincident with any appreciable rise in 11-hydroxyetiocholanolone excretion, one finds a considerable rise in urinary levels of 11-hydroxyandrosterone and 11-ketoetiocholanolone. Thus it would not be reasonable to ascribe the presence of 11-hydroxyetiocholanolone in these normals, and in cancer patients, to a markedly increased secretion of all adrenal hormones, since an associated high level of other adrenocortical metabolites was not evident. It is believed, therefore, that the tendency to production of relatively large amounts of the metabolite 11-hydroxyetiocholanolone reflects a metabolic variant generally present in patients with neoplasia and conceivably in a segment of the normal population whose predisposition towards development of cancer is greater than average.

Group 2, the $\mathrm{C}_{19}$ 11-desoxysteroids, is uniformly the larger component of the $a$-ketonic fraction. The major precursor, in males, of the metabolites in this group is undoubtedly testosterone of gonadal origin. It is equally certain that the adrenal cortex secretes a steroid, or group of steroids, whose metabolic transformation products include $C_{10}$ 11-desoxy compounds. The adrenal contribution to the compounds in this group, however, is normally low (14).

Individual excretion values of the steroids in Group 2, i.e., the $C_{19}$ 11-desoxy steroids, are capable of wide variation as can be seen in Table $I$ and range from $.8 \mathrm{mg}$. per 24 hours to $14.8 \mathrm{mg}$. per 24 hours. It is evident that while there is a large overlap of values, on the average, men 50 years of 
age and over excrete smaller amounts of $\mathrm{C}_{19} 11$ desoxy steroids in their urine than men under 50 as shown in Figure 6. That age alone is not the sole influential factor is evident by striking individual variation in the excretion of this group of substances. These differences in the excretion of 11desoxy steroids by various individuals may well reflect changes in vigor in the broadest meaning of the term and the diversity of values may well suggest the heterogeneity of a segment of a normal population.

Etiocholanolone and androsterone together make up the great bulk of the steroids found in the $\mathrm{C}_{19}$ 11-desoxy group. That there is wide individual variation in the excretion of these two compounds by different subjects is evident from Figure 6 . The tendency toward reduced excretion of these two metabolites with age explains the decreased excretion as a whole of Group 2 ( $\mathrm{C}_{19}$ 11-desoxy) steroids with age, since the other constituents of this group are relatively minor in amount. Mean value for excretion of etiocholanolone in men under 50 years is $4.9 \mathrm{mg}$. per 24 hours and for men 50 years and above it is $2.6 \mathrm{mg}$. per 24 hours. Mean value for excretion of androsterone for these two groups is 3.3 and $1.5 \mathrm{mg}$. per 24 hours, respectively.

A few subjects excrete etiocholanolone and androsterone in approximately a $1: 1$ ratio. In the majority of men, however, etiocholanolone is excreted in greater amount than androsterone. Calculation of the mean etiocholanolone/androsterone ratio of the group under $50(1.7 / 1)$ and the group 50 years and over (2.2/1) suggests that the metabolites of the etiocholane type are relatively greater in the older age group. The overlap is considerable, however, and the difference is not statistically significant.

Unlike their 11-oxygenated analogs, there seems to be a high order of constancy in the tranformation of $\mathrm{C}_{19}$ 11-desoxy precursors to metabolites having a particular type of fusion of the A : B rings of the steroid nucleus. It is apparent from Figure 4 that despite a very wide variation in total output of $C_{19}$ 11-desoxy metabolites, the per cent of these metabolites, excreted as derivatives of etiocholane varies within a narrow range. That this constancy is unrelated to age, or to the per cent of $\mathrm{C}_{19}$ 11-oxygenated etiocholane metabolites is clear from Figure 5. Because of this lack of relationship, it is suggested that the reduction of the $a, \beta$-unsatura- tion in 11-oxy and 11-desoxy precursors with the formation of a particular isomer may have a specific significance in terms of the physiologic action of hormonal precursors.

In addition to etiocholanolone and androsterone, trace amounts of androstanedione and etiocholanedione are found in all urines; $3 \beta$-etiocholanolone is found in trace amounts infrequently. There is a suggestion that the sum total of the "diones" may be higher in those subjects whose etiocholanolone and androsterone output is high, but again exceptions, such as Subject M21 and C21 are apparent. The identification of these three steroids is technically complicated, as has been indicated under "Methods." No discussion of the "preg. group" is warranted because of its inhomogeneity and irregular detection in the chromatographic separation. 17a-hydroxypregnanolone has not

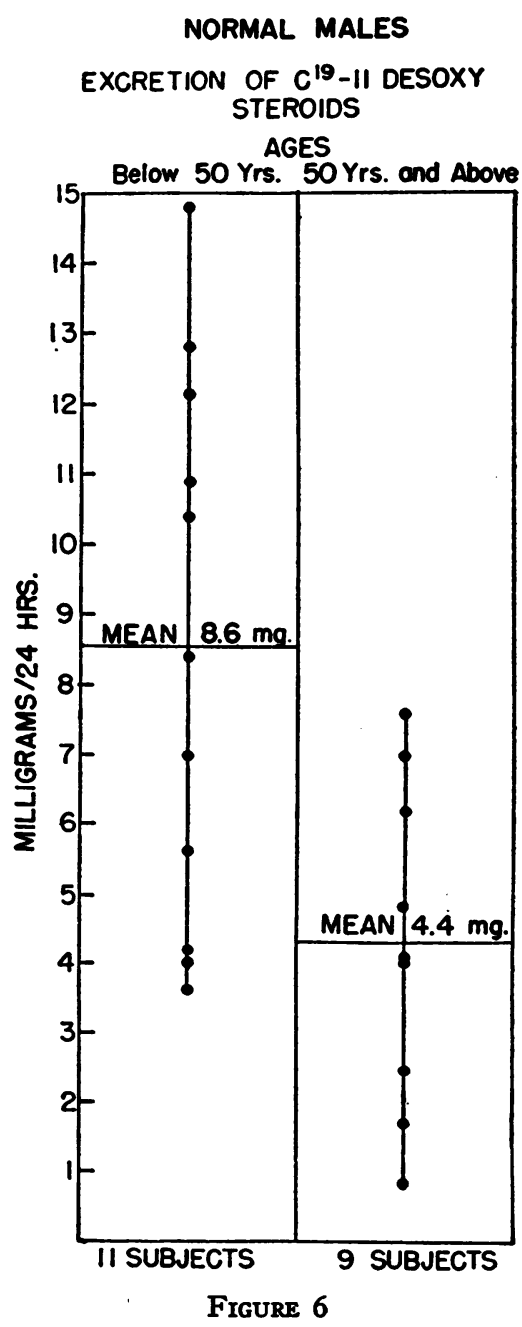


TABLE II

Mean $\alpha$-ketosteroid excretion pattern

\begin{tabular}{lcr}
\hline \multicolumn{1}{c}{ Compounds } & $\begin{array}{c}\text { Men } \\
\text { below 50 }\end{array}$ & $\begin{array}{c}\text { Men 50 } \\
\text { and above }\end{array}$ \\
\hline C $_{19}$ 11-desoxy Compounds & 8.6 & 4.4 \\
11-oxy Compounds & 2.1 & 1.8 \\
11-Ketoetiocholanolone & .9 & .7 \\
11-Hydroxyandrosterone & 1.1 & .8 \\
Etiocholanolone & 4.9 & 2.6 \\
Androsterone & 3.3 & 1.5 \\
Etiocholanedione & trace & trace \\
Androstanedione & trace & trace \\
& & \\
\% $\beta$ of $\alpha+\beta$ & 7.4 & 4.4 \\
$\beta-$ Ketosteroids & 1.1 & .5 \\
$\alpha-$ Ketosteroids & 14.5 & 8.8 \\
Ketonic Ketosteroids & 17.7 & 10.9 \\
Crude Ketosteroids & 23.5 & 22.9 \\
\multicolumn{1}{c}{ Cases } & 11 & 9 \\
\hline
\end{tabular}

been identified in normal male urine. The signifcance of its presence in disease states is thus further established. Isolation of compounds $\mathrm{E}$ and $\mathrm{F}$ and their "tetrahydro" derivatives has been effected in only three subjects. As has been noted previously, the tetrahydro compounds are excreted in greater amounts than their unsaturated precursors. Studies on patients receiving cortisone or ACTH therapy indicate this to be the pattern of excretion at widely varying levels of precursor steroids (15).

There is a great deal of published data on crude ketosteroid excretion in normals and in various disease states, so that these data need not be dealt with extensively. Two points appear worthy of mention. First, the association of ketosteroid output with age is more clearly apparent only as finer fractionation of the ketosteroids is made. The clear distinction between changes in 11-desoxy and 11-oxygenated steroid output can be demonstrated only after extensive separation of crude steroid fractions. The limits to interpretation of crude data are clearly evident. Second, it is worthy of note that the $\beta$-ketosteroid fraction, which has been ascribed to adrenal precursors, undergoes a selective decrease with age, not associated with any apparent alteration of the other adrenal metabolites that have been studied. Elimination of the unusually high values in Subjects K32 and R61 accentuates this selective decrease in the $\beta$-ketosteroid fraction.

Mean values of all the crude and pattern data are presented in Table II where the subjects are divided into two groups, men below the age of 50 , and men 50 years and above in age; 11-hydroxyetiocholanolone is not included for reasons discussed above. Though the limitations of calculating "average" patterns for at least these two groups are apparent from the wide individual variations present, for general comparative purposes this breakdown is useful in that it permits the interpretation of older and less refined data in the light of the information obtained by the extensive and intensive analytical methods employed in the present study.

\section{SUM MARY}

The individual components of the neutral $\alpha$-ketosteroid fraction from urine were determined in twenty normal males ranging in age from 21 to 76 years. After preliminary separation, the steroids were isolated by chromatography and were identified by infrared spectrometry. The principal components in a quantitative sense were $3 a$-hydroxyetiocholane-11,17-dione, 3a,11 $\beta$-dihydroxyandrostane-17-one, etiocholanolone, and androsterone. Other compounds were present in small or trace amounts.

The presence of an oxygen atom at carbon- 11 of the steroid nucleus permitted distinction of metabolites primarily derived from adrenal hormones. By means of this criterion, it was concluded that adrenal function was essentially constant during the decades studied, whereas the level of metabolites, derived primarily from gonadal precursors, diminished in the older group. Despite this trend, there were variations with individual subjects within age groups so that it would appear the determinants of hormone production and metabolism are peculiar to the subject rather than a consequence of chronological age. The significance of these results in the interpretation of hormone physiology was discussed.

\section{ACKNOWLEDGMENTS}

We are grateful to Dr. George Thorn for making available to us the urine on Subjects C21 and B21, and to Dr. Nathan Shock for making available the urine on Subjects K31, R32, R63, C64, M65, and M72.

The authors wish to express their appreciation to the large group of devoted Research Assistants and Technicians who made much of the work possible. The routine chemical and chromatographic separations were carried out by a group under the supervision of Madeleine Stokem and Ruth Jandorek. The colorimetric analyses 
were under the supervision of Alga Teager. The infrared spectrometry was under the supervision of Friederike Herling.

\section{REFERENCES}

1. Dobriner, K., Lieberman, S., and Rhoads, C. P., Studies in steroid metabolism. I. Methods for the isolation and quantitative estimation of neutral steroids present in human urine. J. Biol. Chem., 1948, 172, 241.

2. Mason, H. L., Isolation of adrenal cortical hormones from urine: 17-hydroxycorticosterone and 17- hydroxy-11-dehydrocorticosterone. J. Biol. Chem., 1950, 182, 131.

3. Callow, N. H., Callow, R. K., and Emmens, C. W., Colorimetric determination of substances containing the grouping $-\mathrm{CH}_{2} \cdot \mathrm{CO}$-in urine extracts as an indication of androgen content. Biochem. J., 1938, 32, 1312.

4. Callow, N. H., Callow, R. K., Emmens, C. W., and Stroud, S. W., Methods of extracting compounds related to the steroid hormones from human urine. J. Endocrinol., 1939, 1, 76.

5. Talbot, N. B., Butler, A. M., MacLachlan, E. A., and Jones, R. N., Definition and elimination of certain errors in the hydrolysis, extraction and spectrochemical assay of $\alpha$ and $\beta$-neutral urinary 17-ketosteroids. J. Biol. Chem., 1940, 136, 365.

6. Nelson, D. H., Reich, H., and Samuels, L. T., Isolation of a steroid hormone from the adrenal-vein blood of dogs. Science, 1950, 3, 578.

7. Nelson, D. H., Samuels, L. T., and Reich, H., The cortical steroid in mammalian blood after ACTH stimulation, in Proceedings of the Second Clinical
ACTH Conference, Mote, J. R., Ed., The Blakiston Co., Phila., 1951, 1, 49.

8. Pincus, G., Hechter, O., and Zaffaroni, A., The effect of ACTH upon steroidogenesis by the isolated perfused adrenal gland, in Proceedings of the Second Clinical ACTH Conference, Mote, J. R., Ed., The Blakiston Co., Phila., 1951, 1, 40.

9. Haines, W. J., Aspects of steroid hormone chemistry and physiology. Studies on the biosynthesis of adrenal cortex hormones, in Recent Progress in Hormone Research, Pincus, G., Ed., Academic Press, New York, 1952, 7, 255.

10. Dobriner, K., Lieberman, S., Wilson, H., Ekman, B., Pearson, O., and Eliel, L., Adrenal function and steroid excretion in neoplastic disease, in Proceedings of the First Clinical ACTH Conference, Mote, J. R., Ed., The Blakiston Co., Phila., 1950, 158.

11. Dobriner, K., Lieberman, S., and Rhoads, C. P., The excretion in the urine of metabolites of adrenal cortical hormones in health and disease, including neoplastic growth. Cancer Research, 1947, 7, 711.

12. Dobriner, K., Lieberman, S., Wilson, H., Ekman, B., and Rhoads, C. P., Steroid excretion and adrenal function in neoplastic disease, in Pituitary-Adrenal Function, Chrisman, R. C., Ed., Washington, D. C., in American Association for the Advancement of Science, 1950, 158.

13. Dobriner, $\mathrm{K}$., in Symposium on Steroids in Experimental and Clinical Practice, White, A., The Blakiston Co., Phila., 1951, 130.

14. Dobriner, K., and Lieberman, S., The metabolism of steroid hormones in humans, in A Symposium on Steroid Hormones, in Gordon, E. S., Ed., University of Wisconsin Press, Madison, 1950, 46.

15. Unpublished Data. 